\title{
Virtual reality using games for improving physical functioning in older adults: a systematic review
}

\author{
Karina Iglesia Molina*, Natalia Aquaroni Ricci, Suzana Albuquerque de Moraes and Monica Rodrigues Perracini
}

\begin{abstract}
The use of virtual reality through exergames or active video game, i.e. a new form of interactive gaming, as a complementary tool in rehabilitation has been a frequent focus in research and clinical practice in the last few years. However, evidence of their effectiveness is scarce in the older population. This review aim to provide a summary of the effects of exergames in improving physical functioning in older adults. A search for randomized controlled trials was performed in the databases EMBASE, MEDLINE, PsyInfo, Cochrane data base, PEDro and ISI Web of Knowledge. Results from the included studies were analyzed through a critical review and methodological quality by the PEDro scale. Thirteen studies were included in the review. The most common apparatus for exergames intervention was the Nintendo Wii gaming console (8 studies), followed by computers games, Dance video game with pad (two studies each) and only one study with the Balance Rehabilitation Unit. The Timed Up and Go was the most frequently used instrument to assess physical functioning (7 studies). According to the PEDro scale, most of the studies presented methodological problems, with a high proportion of scores below 5 points (8 studies). The exergames protocols and their duration varied widely, and the benefits for physical function in older people remain inconclusive. However, a consensus between studies is the positive motivational aspect that the use of exergames provides. Further studies are needed in order to achieve better methodological quality, external validity and provide stronger scientific evidence.
\end{abstract}

Keywords: Virtual reality therapy, Video game, Physical exercise, Randomized controlled trial, Aged

\section{Introduction}

The use of virtual reality (VR) using interactive games, as a complementary tool in rehabilitation has been a frequent focus of research since the late 1990's, with a considerable increase in the number of publications in the last few years [1]. VR makes it possible to practice activities within enriched, secure and challenging environments, thereby favoring motor learning and neural plasticity [1,2]. In addition, it is considered to be a feasible strategy for intervention and an alternative complement to conventional exercises [3].

Exercise is well recognized as a beneficial intervention to enhance physical functioning in older adults, ultimately improving overall health [4]. Some studies suggest that exercise using VR in elderly patients promotes improvements in mobility $[5,6]$, in muscular strength of the lower limbs [7], in cognition, mainly of executive

\footnotetext{
* Correspondence: karinaiglesia@msn.com

Master's and Doctoral Programs in Physical Therapy, Universidade Cidade de São Paulo - UNICID, Rua Cesáreo Galeno, 448, 03071-000 Tatuapé, SP, Brazil
}

functions [6], in balance control [1,8-11], in reaction time [5] and also helps to prevent falls $[1,12,13]$. Although these studies might be compelling, there is not enough evidence to support that exercises using VR would promote better or even similar improvements in physical functioning, when compared with regular exercise programs[14].

Older people present diminished mobility and balance control as a result of morphological and functional changes in the central and peripheral nervous system related to age [15], to the presence of illnesses and to disuse. In order to overcome these negative changes, challenging, intensive and repetitive motor training through specific therapeutic exercises, such as those involving multi-segment coordination, anticipatory postural adjustments and tasks with divided attention can be used to enhance neuroplasticity $[15,16]$. However the use of exergaming could optimize motor learning by combining physical and cognitive demands in an attractive and interactive way, motivating players to focus 
their attention not on the movements itself, but on the outcome of the movements in the game [2,17].

There is a greater interest in the use of VR for therapeutic purposes [14,17-25]. Systematic reviews concerning VR have been carried out in populations with specific health conditions, such as post-stroke patients and those with balance disturbances or falls [18,20,22-24], within different therapeutic settings [21] and in samples covering a range of age groups $[14,17]$. Minor or inconclusive positive improvements have been demonstrated with the use of VR in individual studies. However, systematic reviews reveal notable lack of significant methodological quality studies and reinforce that there is insufficient information to recommend interventions with exercise using VR [14,21]. Particularly, the evidence is scarce regarding the efficacy and effectiveness of using VR through games, on an isolated basis or in addition to conventional motor therapies in the older population. Thus, the aim of this systematic review is to investigate the effectiveness of exercises using interactive games (exergames) in improving physical functioning in older adults.

\section{Review \\ Method \\ Electronic search}

To verify the range of publications on interventions through exercises using VR games in older people, searches were made on the following data bases: EMBASE, MEDLINE, PsyInfo, Cochrane data base, PEDro and ISI Web of Knowledge. Four thematic blocks were used with a series of synonyms and variants related to 1) virtual reality with games, 2) exercises/physiotherapy, 3) aged and 4) randomized clinical trial. The words in a single block were combined among themselves with the use of the OR boolean operator and the interaction between blocks with the AND operator, in accordance with the example: ((user-computer interface) OR (computers or microcomputers or computer systems or software) OR (computer simulation or computer-assisted instruction or therapy computer-assisted) OR (computer graphics or video games or touch) OR (virtual reality* or virtual-reality* or VR) OR (computer game* or computer interact*) OR (computer assist* therap* or computer assist* treat*) OR (computer generat* environment* or computer generat* object) OR (video game*) OR (haptics or haptic device*) OR (user computer interface)) AND ((exercise) OR (exercise movement techniques) OR (exercise therapy) OR (biofeedback) OR (exercis* or training or biofeedback ) OR (physical fitness) OR (exercise tolerance) OR (sports) OR (physical endurance) OR (exertion $^{*}$ ) OR (exercis*) OR (sport*) OR (physical fitness or motion fitness or physical therap*) OR (physical* endur*) OR (strength* or isometric* or isotonic* or isokinetic* or aerobic* or endurance or weight $^{*}$ ) OR (train*) OR (physical therapy modalities) OR (physiotherap*) OR (kinesiotherap*) OR (rehabilitation or rehab*) OR (resistance training) OR (exercis* or training)) AND ((older adult or older people or older person* or elderly or seniors or geriatric or frail or aged)) AND ((randomized controlled trial*) or (controlled clinical trial) or (random allocation) or (double-blind method) or (single-blind method) or (clinical trial) or (placebo) or (random*) or $\left(\right.$ blind $\left.{ }^{*}\right)$ ).

The search was conducted from July to October 2013 being limited to scientific articles and with no restrictions regarding language and publication year. In addition, a manual search was carried out to complement the strategy of looking up research on the topic.

\section{Study selection}

This review included randomized controlled clinical trials with a sample of older adults ( $\geq 60$ years old) and main intervention of VR with physical exercises by way of interactive games that aimed at rehabilitation. The VR exergames treatment could be on an isolated basis or combined with other interventions. For comparison, the control could be either with no intervention or conventional treatment (physical exercises, functional training or education). To be considered a game was necessary to fill out at least some of the following characteristics: interactivity, entertainment, rules, presence of an opponent or the objective to win points, and the possibility of winning or losing.

Studies were excluded if they had only cognitive outcomes, samples composed of participants with specific clinical conditions (i.e. stroke, Parkinson, dementias, diabetes mellitus, vestibulopathy), game performed in sit position, VR just provides visual information and insufficient description of statistical analysis.

For the selection of studies, the publications resulting from the searches had their titles and abstracts analyzed by two independent assessors. The articles selected for reading were once again analyzed in terms of criteria for eligibility. In the case of discordances, in any phase of the selection process, a third reviewer was called in for a consensus analysis. The studies included for the final review were analyzed in terms of methodology with the extraction of data regarding the sample composition, interventions and outcomes description, and the effects of the interventions.

\section{Outcomes}

The primary outcomes considered were mobility-related physical functioning measures. Emphasis was placed on measurements for physical mobility and body balance through objective and/or subjective tests and instruments that are easily interpreted and used in clinical practice. Secondary outcomes included measurements 
relating to body structure and function, such as laboratorial posture control (ie. postural sway test and dynamic posturography), muscle strength (ie. maximal isometric muscle force and grip strength), reaction time and laboratory gait measurement.

\section{Methodological analysis and quality}

The methodological quality of the studies was assessed using the PEDro scale. This scale analyses 11 items for the interpretation of research relating to the internal and external validity of clinical trials in physiotherapy [26]. The PEDro total score varies from zero to 10 , with no score for the first item and the higher the score the better the methodological quality of the clinical trial. The ranking of the studies is available in the PEDro database [27]. In the absence of this ranking at PEDro database two assessors conducted the ranking on an independent basis and if there was disagreement, a third assessor was called in to reach a consensus.

Due to the variability between the interventions proposed and small study sample sizes it was not possible to conduct a metanalysis. A critical review analysis of the contents was performed.

\section{Results}

As shown in Figure 1, a total of 2,940 references were found via the data base and manual searches. After the removal of duplicated references, the titles and abstracts were analyzed for 2,802 studies, with 28 articles being pre-selected for full reading. Of these, 15 were excluded because they failed to fit the inclusion criteria for this review, resulting in 13 articles for critical analysis of content. The synopsis of the articles analyzed can be found in Tables 1 and 2, in accordance with the type of device used (Wii console or others). The great majority of these articles $(n=11)[6-10,12,13,28-31]$ was published in the last 2 years.

\section{Sample characteristics}

The samples composition of the 13 studies varied from 12 to 58 participants divided between control group and intervention group. The samples included both sexes, with a higher proportion of women [6-12,28-32]. Just one of the studies failed to report the proportion of sexes in the sample [13]. Five studies presented a sample size calculation $[7,10,12,13,29]$ and among these just one had its data analyzed with the initially calculated sample size [29].

Four studies were conducted with community-dwelling elders $[9,13,28,30]$, four with older people from a housing facility/ senior living community $[6,7,10,31]$, three studies took their samples from outpatient clinics (falls and balance clinic/ orthopedic and balance) $[8,12,32]$, one study recruited inpatients from a geriatric hospital rehabilitation unit [29], and other older adults attending day hospital [11]. Despite being in different therapeutic settings, the

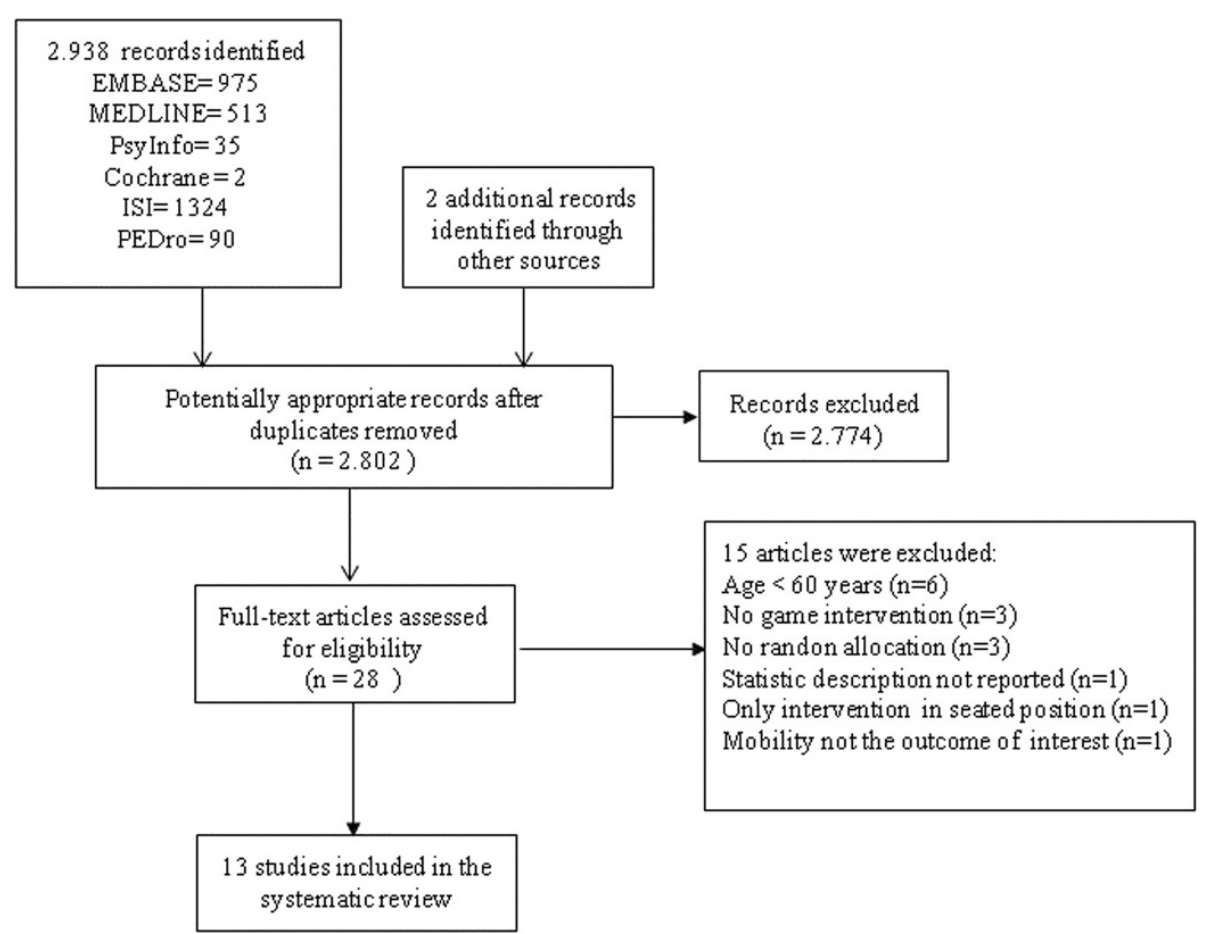

Figure 1 Flowchart of literature search. 
Table 1 Data summary of randomized clinical trials using exergames with the Nintendo Wii gaming console

Study Sample $\quad$ Trial Desing Outcomes Intervention

\begin{tabular}{ll}
\hline Study & Sample \\
\hline Bieryla \& $\&$ ] & $\begin{array}{l}\text { Healthy older } \\
\text { adults from a } \\
\text { local senior } \\
\text { living } \\
\text { community. }\end{array}$ \\
& $\mathrm{N}=12$ \\
& \\
& $81.5 \pm 5.5$ yrs \\
& $\begin{array}{ll}\text { EG: } n=6 \\
\text { (withdraw }=1 \text { during } \\
\text { treatment and } \\
\text { 1at follow-up) } \\
\text { CG: } n=6 \\
\text { (withdraw }=1 \text { ) } \\
\text { Community }\end{array}$ \\
Franco & (w)
\end{tabular}

Randomized

1) BBS Intervention

Randomized
controlled

trial with

one month

follow-up.

EG: Wii Balance Board with Wii Fit.

Effects Observed

- BBS scores significantly increased for EG

participants. Post hoc analysis indicated a

significant increase from pre-intervention to

1 month post-intervention but not a significant

increase from pre-intervention to 1 week

post-intervention. BBS score did not significantly change in the CG.

- There was no significant improvement in $F A B$,

FRT and TUG for either group.

exercises and activities chosen from the yoga (half moon, chair, warrior), aerobic (torso

twists), and balance games (soccer heading, ski jump) modes.

Individual sessions 3x/week (30 min each session) for 3 weeks.

et al. [28] dwelling elders at low-income senior housing

facility.

$N=32$

CG: No intervention.

EG1: Wii Fit.

Randomized

controlled trial.

1) $B B S$

4) TUG

5 Wii Fit balance training games (soccer heading, ski jumping- slalom, tightrope, table tilt and balance bubble) with supplementa home exercises (balance and flexibility- daily).
$78.27 \pm 6$ yrs
3) SF-36.

$E G 1: n=11$

$E G 2: n=11$

CG: $n=10$

Jorgensen Community-

et al. [7] dwelling older adults.

Randomized controlled

trial. contraction (MVC) of leg extensors.
1) Maximal voluntary

4) Wii Fit Enjoyment Questionnaire.

- Individual sessions $2 x / w$ session) for 3 weeks.

EG2: Matter of Balance program (MOB). The program uses a cognitive restructuring for coping strategies, strength training exercises (elastic resistance band) for strength and balance tasks to reduce fall risk.

Group sessions 2x/week (30-45 min each session) for 3 weeks.

CG: No intervention

EG: Nintendo Wii training.

- Balance tests (BBS and Tinetti) improved in all 3 groups after the intervention period. There was a significant main effect of time (pre- to post-intervention) but no interaction between time (pre and post) and groups (Wii Fit, MOB, Control).

- The groups were different at pre-test in SF-36 scores. There was no significant time change in SF-36 scores and non-significant group-time interaction.

- 81\% of the EG1 participants reported high levels of enjoyment while playing the Wii games.

- Between-group difference (pre-to-post changes) favoring the EG were evident in the MVC, RFD, 
Table 1 Data summary of randomized clinical trials using exergames with the Nintendo Wii gaming console (Continued)

\begin{tabular}{|c|c|c|c|c|c|}
\hline & & & & & $\begin{array}{l}\text { TUG, FES-I, and Chair Stand Test. The } \\
\text { CoP-VM did not differ between groups. }\end{array}$ \\
\hline & \multicolumn{2}{|l|}{$N=58$} & $\begin{array}{l}\text { 2) Postural balance- } \\
\text { center of pressure velocity } \\
\text { moment (CoP-VM). }\end{array}$ & $\begin{array}{l}\text { Each training session was designed to include } \\
\text { balance exercise games followed by a muscle } \\
\text { exercise sequence. The participants could choose } \\
\text { freely between } 5 \text { balance games (table tilt, slalom ski, } \\
\text { perfect } 10 \text {, tight rope tension, penguin slide), whereas } \\
\text { a single exercise (standing rowing squat) was used } \\
\text { for muscle conditioning. }\end{array}$ & $\begin{array}{l}\text { - EG participants either agreed or } \\
\text { strongly agreed with the statement } \\
\text { that Wii training was fun and } \\
\text { motivating. }\end{array}$ \\
\hline & \multicolumn{2}{|l|}{$75 \pm 6$ yrs } & 3) Rapid force capacity (RFD). & $\begin{array}{l}\text { - Individual sessions 2x/week ( } 35 \text { to } 40 \text { min each } \\
\text { session) for } 10 \text { weeks }\end{array}$ & \\
\hline & \multicolumn{2}{|l|}{$\begin{array}{l}\text { EG: } \mathrm{n}=28 \\
\text { (withdraw }=7 \text { ) }\end{array}$} & 4) TUG. & CG: EVA insoles as placebo. & \\
\hline & \multicolumn{2}{|l|}{$\begin{array}{l}\text { CG: } \mathbf{n}=30 \\
\text { (withdraw }=2 \text { ) }\end{array}$} & 5) FES-I. & $\begin{array}{l}\text { The participants in CG were instructed to wear EVA } \\
\text { insoles in their shoes everyday for the entire duration } \\
\text { of the trial. They received phone calls to check that } \\
\text { problems with the EVA insoles had not emerged. }\end{array}$ & \\
\hline & & & $\begin{array}{l}\text { 6) } 30-s e c \text { repeated Chair } \\
\text { Stand Test. }\end{array}$ & & \\
\hline & & & $\begin{array}{l}\text { 7) Likert scale regarding } \\
\text { motivation toward Wii } \\
\text { training. }\end{array}$ & & \\
\hline \multirow[t]{4}{*}{$\begin{array}{l}\text { Laver } \\
\text { et al. [29] }\end{array}$} & Geriatric Hospital & $\begin{array}{l}\text { Feasibility } \\
\text { Randomized } \\
\text { controlled trial. }\end{array}$ & 1) TUG. & EG: Nintendo Wii training. & $\begin{array}{l}\text { - There was no difference between } \\
\text { groups on univariable analyses for any } \\
\text { measures. }\end{array}$ \\
\hline & Rehabilitation & & 2) SPPB. & $\begin{array}{l}\text { Treatment focused on balance tasks (weight shift on the } \\
\text { balance board), strength exercises for the lower limb } \\
\text { (sustained squats or single leg extension) and aerobic } \\
\text { capacity (stepping on and off the balance board } \\
\text { or walking on the spot). }\end{array}$ & $\begin{array}{l}\text { Multivariable analyses (based on the } \\
\text { number of intervention sessions) } \\
\text { adjusting for length of stay, age, } \\
\text { gender and baseline FIM showed } \\
\text { that EG improved more on TUG and } \\
\text { MBBS. }\end{array}$ \\
\hline & Unit. & & 3) Modified BBS. & $\begin{array}{l}\text { Individual sessions } 5 x / \text { week ( } 25 \text { min each session) for } \\
\text { the duration of the participant's stay on the unit. }\end{array}$ & $\begin{array}{l}\text { - No statistically significant differences } \\
\text { were found between groups for the } \\
\text { SPPB, Timed IADL Test, ABC Scale or } \\
\text { EQ5D. }\end{array}$ \\
\hline & $N=44$ & & 4) $\mathrm{TIADL}$. & CG: Conventional physiotherapy. & $\begin{array}{l}\text { - In either groups, participants reported } \\
\text { some discomfort, being musculoskeletal } \\
\text { pain the most frequent one. Within the } \\
\text { CG, } 1 \text { serious adverse event (conscious } \\
\text { collapse- vasovagal). Three } \\
\text { participants from the EG fell while on } \\
\text { the unit in comparison to one fall } \\
\text { reported from CG. }\end{array}$ \\
\hline
\end{tabular}


Table 1 Data summary of randomized clinical trials using exergames with the Nintendo Wii gaming console (Continued)

\begin{tabular}{|c|c|c|c|c|c|}
\hline & & & & $\begin{array}{l}\text { Treatment sessions included walk, transfers practice, } \\
\text { walk up and down steps, balance tasks (standing on a } \\
\text { foam block, tapping a balloon or reaching for objects), } \\
\text { strength (e.g. use of light weights } \\
\text { or stretches), aerobic and flexibility exercises. }\end{array}$ & \\
\hline & $\begin{array}{l}E G: n=22 \\
\text { (withdraw }=2 \text { ) }\end{array}$ & & 6) ABC Scale. & $\begin{array}{l}\text { - Individual sessions } 5 x / \text { week ( } 25 \text { min each session) } \\
\text { for the duration of the participant's stay on the unit. }\end{array}$ & \\
\hline & CG: $n=22$ & & 7) EQ5D. & & \\
\hline & & & $\begin{array}{l}\text { 8) Participant reports of } \\
\text { discomfort and adverse } \\
\text { events. }\end{array}$ & & \\
\hline \multirow[t]{9}{*}{$\begin{array}{l}\text { Maillot \& } \\
\text { Perrot [6] }\end{array}$} & $\begin{array}{l}\text { Independent } \\
\text { older adults. }\end{array}$ & $\begin{array}{l}\text { Randomized } \\
\text { controlled } \\
\text { trial. }\end{array}$ & 1) Physical Measures: & EG: Nintendo Wii training. & $\begin{array}{l}\text { - Follow-up tests showed greater } \\
\text { improvement in the EG than in the CG } \\
\text { for all the physical measures except the } \\
\text { Back-Scratch upper-right and the Borg } \\
\text { Scale ratings. }\end{array}$ \\
\hline & $N=32$ & & - chair-stand test; & $\begin{array}{l}\text { Each session began with a warm-up and } \\
\text { finished with a cool-down. The main session } \\
\text { comprises games from the Wii Sports, Wii Fit, } \\
\text { and Mario \& Sonic on Olympic Games. The } \\
\text { participants' pairs change at each session } \\
\text { with the intention of making the exergame playing } \\
\text { more enjoyable and motivating adherence to the } \\
\text { regimen. }\end{array}$ & $\begin{array}{l}\text { - The comparisons for measures of } \\
\text { executive function and processing } \\
\text { speed show that improvement was } \\
\text { significantly greater in the EG than } \\
\text { in the CG. }\end{array}$ \\
\hline & 65 to 78 yrs & & - arm curl test; & $\begin{array}{l}\text { Pairs sessions 2x/week ( } 30 \text { min each session) } \\
\text { for } 12 \text { weeks. }\end{array}$ & $\begin{array}{l}\text { - For measures of visuospatial function, } \\
\text { the difference between the EG and CG } \\
\text { was not significant. }\end{array}$ \\
\hline & $\begin{array}{l}\text { EG: } \mathrm{n}=16 \\
\text { (withdraw }=1 \text { ) }\end{array}$ & & $\begin{array}{l}\text { - } 6 \mathrm{MW} \text { (meters, borg scale } \\
\text { max and mean HR); }\end{array}$ & CG: No intervention. & $\begin{array}{l}\text { - } 80 \% \text { of EG participants agreed that } \\
\text { the exergame training was manageable } \\
\text { for seniors. All participants reported } \\
\text { that they would like to continue with } \\
\text { exergame activity, however only } \\
40 \% \text { considered acquiring a game } \\
\text { console. }\end{array}$ \\
\hline & $\begin{array}{l}\text { CG: } n=16 \\
\text { (withdraw }=1 \text { ) }\end{array}$ & & - chair-sit-and-reach test; & & \\
\hline & & & - back-scratch test; & & \\
\hline & & & - $8 \mathrm{ft} \mathrm{UG.}$ & & \\
\hline & & & 2) Cognitive battery: & & \\
\hline & & & $\begin{array}{l}\text { - executive control tasks (Trail- } \\
\text { Making test, Stroop Color Word } \\
\text { Interference test, Letter Sets test, }\end{array}$ & & \\
\hline
\end{tabular}


Table 1 Data summary of randomized clinical trials using exergames with the Nintendo Wii gaming console (Continued)

\begin{tabular}{|c|c|c|c|c|c|c|}
\hline & & & $\begin{array}{l}\text { Matrix Reasoning test2, Digit } \\
\text { Symbol Substitution test); }\end{array}$ & & & \\
\hline & & & $\begin{array}{l}\text { - visuospatial tasks (Spatial Span } \\
\text { test, Directional Headings test, } \\
\text { Mental Rotation test) }\end{array}$ & & & 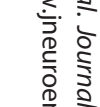 \\
\hline & & & $\begin{array}{l}\text { - processing-speed tasks } \\
\text { subdivided into two categories: } \\
\text { perceptual speed (Cancellation } \\
\text { test and Number Comparison } \\
\text { test) and psychomotor speed } \\
\text { (the Reaction Time test and } \\
\text { Plate Tapping test). }\end{array}$ & & & 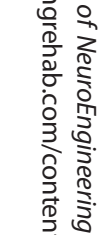 \\
\hline & & & $\begin{array}{l}\text { 3) Impression questionnaire } \\
\text { of the exergame program. }\end{array}$ & & & \\
\hline $\begin{array}{l}\text { Pluchino } \\
\text { et al. [10] }\end{array}$ & Independent seniors. & $\begin{array}{l}\text { Randomized } \\
\text { controlled trial- } \\
\text { pilot study. }\end{array}$ & 1) TUG. & $\begin{array}{l}\text { EG 1: Standardized Balance Exercise. Program } \\
\text { consisted of } 14 \text { functional activities with a } \\
\text { pronounced demand for balance (stepping } \\
\text { on a compliant surface, walking forward } 10 \\
\text { steps and pivoting } 180^{\circ} \text {, alternately moving a } \\
\text { weight between a high and low shelf } \\
\text { situated just beyond } 1 \text { arm's length and more). }\end{array}$ & $\begin{array}{l}\text { - Significant increase in COP area across } \\
\text { time (pre to post-test) was seen for the } \\
\text { three groups. Differences were detected } \\
\text { for the COP anterior-posterior excursion } \\
\text { (max/ min/ SD) and velocity (max/min); } \\
\text { and COP medial-lateral excursion (min) } \\
\text { and velocity (max). No significant group } \\
\text { X time interactions were detected for } \\
\text { any COP measurements. }\end{array}$ & 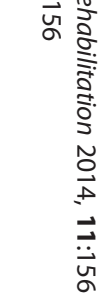 \\
\hline & $N=40$ & & 2) OLS. & EG 2: Tai Chi program. & $\begin{array}{l}\text { - For dynamic posturography, significant } \\
\text { improvements in the overall score } \\
\text { (dynamic movement analysis score), } \\
\text { and in } 2 \text { of the } 3 \text { linear and angular } \\
\text { measures were seen for the sample. }\end{array}$ & \\
\hline & $72.5 \pm 8.40$ yrs & & 3) FRT. & $\begin{array}{l}\text { The program was based on the Tai Chi } \\
\text { Sun-style. The program consisted of } 12 \\
\text { movements using small forward and } \\
\text { backward steps, as well as weight transfers } \\
\text { from one leg to the other. The form also } \\
\text { focused on posture alignment, slight } \\
\text { bending of the knees and moving slowly } \\
\text { with a gentle resistance. }\end{array}$ & $\begin{array}{l}\text { - No significant differences were seen } \\
\text { on time or group (EG1, EG2, EG3) X time } \\
\text { (pre-post) interaction for any field test or } \\
\text { questionnaire. }\end{array}$ & \\
\hline & $\begin{array}{l}\text { EG1: } n=14 \\
\text { (withdraw =6) }\end{array}$ & & 4) Tinetti- POMA. & EG 3: Wii Fit Balance Program. & & \\
\hline & $\begin{array}{l}\mathrm{EG} 2: \mathrm{n}=14 \\
\text { (withdraw }=3 \text { ) }\end{array}$ & & $\begin{array}{l}\text { 5) Postural Sway Test (force } \\
\text { plate): COP area and velocity } \\
\text { for medial-lateral/ anterior- } \\
\text { posterior directions. }\end{array}$ & $\begin{array}{l}\text { Games used for the balance program were: } \\
\text { soccer heading, ski slalom, ski jump, table tilt, } \\
\text { tightrope walk, river bubble, penguin slide, } \\
\text { snowboard slalom and lotus focus. The } \\
\text { games were based on the control of an } \\
\text { on-screen avatar using body movements that } \\
\text { are detected by the balance board. The } \\
\text { training starts with participants playing each }\end{array}$ & & \\
\hline
\end{tabular}


Table 1 Data summary of randomized clinical trials using exergames with the Nintendo Wii gaming console (Continued)

\begin{tabular}{|c|c|c|c|}
\hline & & $\begin{array}{l}\text { strength, proprioception, flexibility, static balance } \\
\text { with EO/ EC and dynamic balance. The difficulty } \\
\text { of the exercises was increased at each session. }\end{array}$ & $\begin{array}{l}\text { improved significantly only in the static } \\
\text { part of the test. }\end{array}$ \\
\hline$N=36$ & 2) Tinetti- POMA. & EG2: Wii Fit training. & $\begin{array}{l}\text { - The number of times the suspended } \\
\text { foot touched the floor during the OLS } \\
\text { in EO/EC conditions decreased } \\
\text { significantly after training for EG1 } \\
\text { and EG3. }\end{array}$ \\
\hline $75.09 \pm 10.26$ yrs & $\begin{array}{l}\text { 3) Wii Fit tests (center } \\
\text { of gravity). }\end{array}$ & $\begin{array}{l}\text { The participants used the Nintendo standardized } \\
\text { video games (heading soccer, ski jumping, yoga, } \\
\text { downhill skiing, game balls and tightrope walker). } \\
\text { The training was personalized because the progress } \\
\text { in training was based on the different levels into } \\
\text { each video game. }\end{array}$ & $\begin{array}{l}\text { - The percentage difference between } \\
\text { right and left (center of gravity position) } \\
\text { was significantly modified for EG3 and } \\
\text { EG2, but no significant difference } \\
\text { appeared in EG1 after treatment. }\end{array}$ \\
\hline$E G 1: n=9$ & & $\begin{array}{l}\text { EG3: Adapted Physical Activities (30 min) + Wii Fit } \\
\text { Training (30 min). }\end{array}$ & $\begin{array}{l}\text { - There was no significant difference } \\
\text { between pre and post-tests for the CG. }\end{array}$ \\
\hline$E G 2: n=9$ & & $\begin{array}{l}\text { Training for EG3 were the same, but the number } \\
\text { of repetitions was lower than the EG1 and EG } 2 \text {. }\end{array}$ & \\
\hline$E G 3: n=9$ & & $\begin{array}{l}\text { EG1/EG2/EG3: All subjects trained 1x/week } \\
\text { (1 hour each session) for } 20 \text { weeks. }\end{array}$ & \\
\hline CG: $n=9$ & & $\begin{array}{l}\text { CG: The subjects } \\
\text { watched television, } \\
\text { played board games } \\
\text { but no physical } \\
\text { training was done. }\end{array}$ & \\
\hline
\end{tabular}

$6 \mathrm{MW}=6$ minute walk test; $8 \mathrm{ft} \mathrm{UG}=8$ foot Up and Go; $\mathrm{ABC}$ Scale = The Activities-specific Balance Confidence Scale; $\mathrm{BBS}=$ Berg Balance Scale; $\mathrm{CG}=\mathrm{Control}$ Group; $C O P=C$ Center of Pressure; DMA = Dynamic Motion Analysis; EG = Experimental Group; EQ5D = EuroQOL Five Dimensions Questionnaire; FAB = Fullerton Advanced Balance; FES-I = Falls Efficacy Scale International; FIM = Functional Independence Measure; FROP-Com = Falls Risk for Older People-Community Setting; FRT = Functional Reach Test; GDS = Geriatric Depression Scale; MBBS = Modified Berg Balance Scale; OLS = One Leg Stance SF-36 = SF-36 health survey; SPPB = Short

Physical Performance Battery; TUG = Timed Up and Go; TIADL = Timed Instrumental Activities of Daily Living; Tinetti-POMA = Tinetti Performance Oriented Mobility Assessment. 
Table 2 Data summary of randomized clinical trials using exergames with other devices

\begin{tabular}{|c|c|c|c|c|c|}
\hline Study & Sample & Trial Desing & Outcomes & Intervention & Effects Observed \\
\hline \multirow[t]{3}{*}{$\begin{array}{l}\text { Duque } \\
\text { et al. [12] }\end{array}$} & $\begin{array}{l}\text { Community-dwelling } \\
\text { elderly whit history of } \\
\text { falls from the Falls and } \\
\text { Fractures Clinic. }\end{array}$ & $\begin{array}{l}\text { Randomized } \\
\text { controlled trial. }\end{array}$ & $\begin{array}{l}\text { 1) Posturography (BRU) } \\
\text { at six different } \\
\text { conditions: }\end{array}$ & EG: Balance Rehabilitation Unit (BRU). & $\begin{array}{l}\text { - After } 6 \text { weeks of intervention the EG } \\
\text { showed significant increase in LOS and } \\
\text { smaller elliptical areas of the EC on hard } \\
\text { surface/ foam, optokinetic stimuli, and } \\
\text { vertical/ horizontal visual-vestibular condition. }\end{array}$ \\
\hline & $N=60$ & & - LOS; & $\begin{array}{l}\text { Treatment is consisted of visual-vestibular } \\
\text { rehabilitation while standing and postural } \\
\text { training virtual reality games (maze, breakfast } \\
\text { and surfing) with increasing levels of } \\
\text { complexity as the individual reported higher } \\
\text { confidence and demonstrated learning of } \\
\text { the correct postural control techniques } \\
\text { required to pass to a higher level } \\
\text { (maximum of } 15 \text { levels). }\end{array}$ & $\begin{array}{l}\text { - After } 9 \text { months, as compared with the } \\
\text { CG, the EG showed significantly higher } \\
\text { level of LOS, and significantly smaller } \\
\text { COP areas in the optokinetic stimuli } \\
\text { and both vertical/ horizontal visual-vestibular } \\
\text { condition. Elliptical areas of the EC on hard } \\
\text { surface/ foam returned to the } \\
\text { baseline values for EG. }\end{array}$ \\
\hline & $\begin{array}{l}\mathrm{EG}: \mathrm{n}=30 \\
\text { (withdraw }=2 \text { ) }\end{array}$ & & - COP EO/ EC on hard surface; & $\begin{array}{l}\text { - Individual sessions } 2 x / \text { week (at least } 30 \text { min } \\
\text { each session) for } 6 \text { weeks. After } 6 \text { weeks } \\
\text { participants received the usual care until }\end{array}$ & $\begin{array}{l}\text { - EG subjects reported a significantly lower } \\
\text { number of falls and lower SAFFE score as } \\
\text { compared with the CG. }\end{array}$ \\
\hline
\end{tabular}
$79.3 \pm 10$ yrs
CG: $\mathrm{n}=3075 \pm 8$ yrs
- COP EC on foam;
- COP optokinetic stimuli;

Schoene Residents at

$\begin{aligned} & \text { independent-living units. } \text { controlled } \\ & \text { trial- pilot }\end{aligned}$

study.

$N=37$
- COP horizontal/ vertical

visual-vestibular condition;

2) Fall history.

3) Gait pattern (GAIT Rite ${ }^{\oplus}$

instrumented walkway): velocity, cadence, stride length and double support time.

4) Grip strength using a hand

dynamometer.

5) Venous blood.

6) GDS.

7) SAFFE.

1) CSRT using a step pad: reaction time, movement time and total response time.

2) PPA:

CG: Usual care.

All participants were given general

recommendations and an evidence-based

care plan on falls prevention.

- 9 months.

EG: A computer unit and step pad at home.

The game required participants to synchronize their stepping with instructions presented on the screen. For each step, score and feedback was given in the center of the screen (perfect,
- Compared to the CG, the EG significantly improved their CSRT, PPA composite scores, as well as the postural sway and contrast sensitivity PPA sub-component scores. In 
Table 2 Data summary of randomized clinical trials using exergames with other devices (Continued)

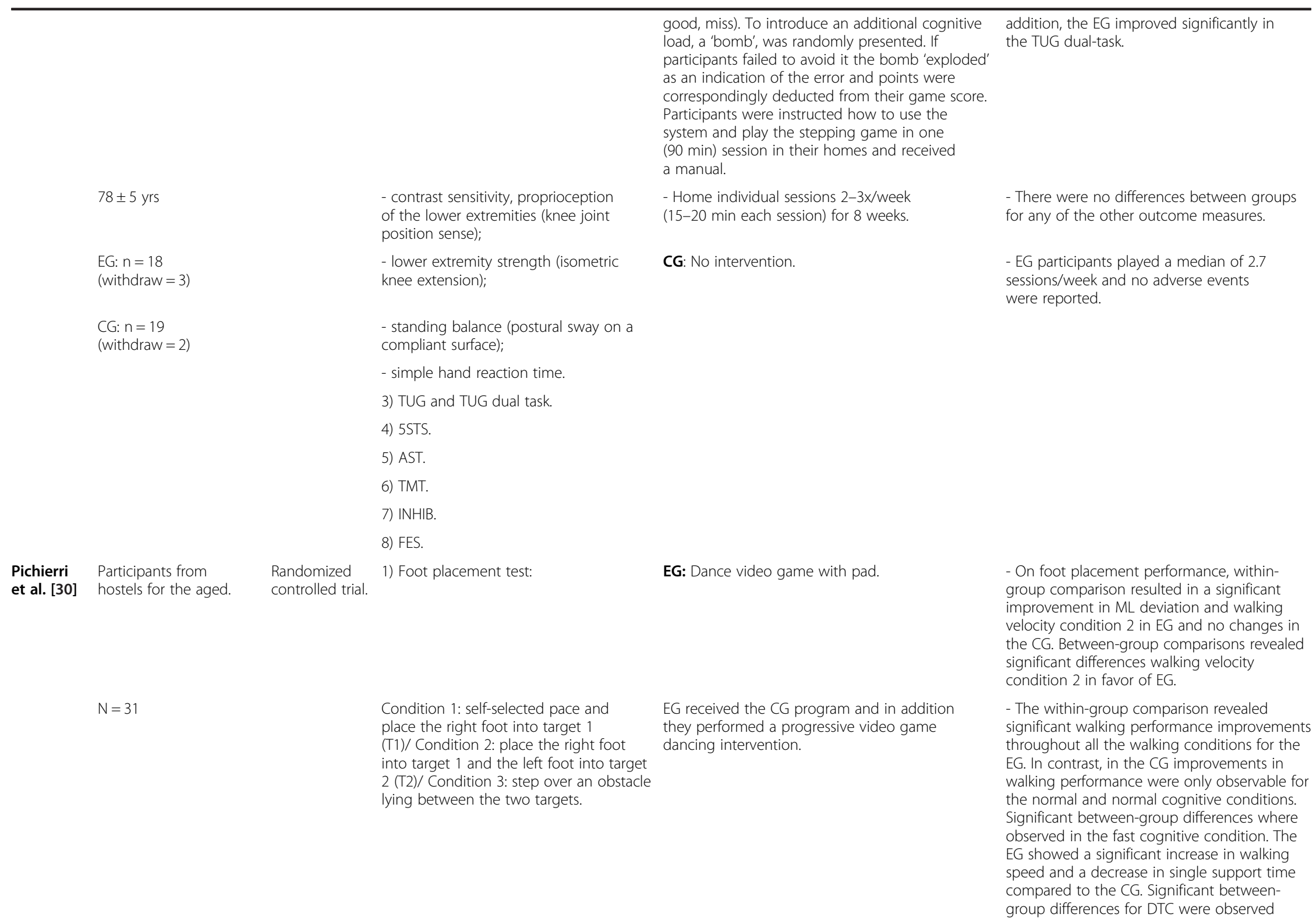


EG: $n=15$

(withdraw $=4$ )

CG: $\mathrm{n}=16$

(withdraw =5)
- M-L/ A-P deviation;

- walking velocity condition

2 and $3 ;$

-M-L/ A-P contact with leading

foot

- contact with subsequent foot:

- wrong foot.

2) Gait analysis: (GAITRiteW

Platinum Version 4.0 software

and the electronic

walkway)

- Normal/ Fast/ Normal cognitive/ Fast cognitive: velocity, cadence,

step time, cycle time, stance

time, single/double support

time, step length;

- dual task costs (DTC) of

walking: percentage of loss

relative to the single task

walking performance

(normal and fast walking).

3) Gaze behavior

4) FES-I. for the parameter single support time for both normal and fast walking speed favoring EG.

The dance video game was projected on a white wall and performed on metal dance pads. A scrolling display of arrows moving upwards across the screen cued each move and the participants were asked to execute the indicated steps (forward, backward, right, or left) when the arrows reached the fixed raster graphic at the top of the screen, and in time with different songs. As the levels increased additional distracting visual cues, e.g., "bombs," were presented and participants had to ignore these cues and focused on the arrows.

Group sessions 2x/ week (40 min each

physical program session) and in addition individual video game sessions (10-15 min) training for 12 weeks.

CG: Physical exercise program with progressive resistance and postural balance. The training session consisted of a warm-up (5 min), resistance training (25 $\mathrm{min}$ ), and balance exercises $(10 \mathrm{~min})$.

Group sessions 2x/ week (40 min each

FES-I questionnaire showed a reduction of concerns about falling in both groups after treatment. Between-group comparison resulted in no significant differences. 
Table 2 Data summary of randomized clinical trials using exergames with other devices (Continued)

\begin{tabular}{|c|c|c|c|}
\hline \multirow[t]{3}{*}{$\begin{array}{l}\text { Szturm } \\
\text { et al. [11] }\end{array}$} & $\begin{array}{l}\text { Community-dwelling } \\
\text { older adults attending } \\
\text { at day hospital. }\end{array}$ & $\begin{array}{l}\text { Randomized } \\
\text { controlled trial. }\end{array}$ & 1) $\mathrm{BBS}$. \\
\hline & $N=30$ & & 2) TUG. \\
\hline & $\begin{array}{l}\text { EG: } n=14 \\
\text { (withdraw }=1 \text { ) }\end{array}$ & & $\begin{array}{l}\text { 3) Spatial-temporal gait pattern } \\
\text { (gait speed, swing time, stance } \\
\text { duration, double support, single } \\
\text { support times, step length and } \\
\text { step width). }\end{array}$ \\
\hline
\end{tabular}

$81 \pm 7 \mathrm{yrs}$
5) MCTSIB - composite loss of balance (LOB) count for stability tasks performed on a fixed floor and on a compliant surface.

- standing EO/ EC;

- cyclic L/R head rotation;

- cyclic arm lifting and lowering task; - cyclic L/R trunk rotations;
EG: Program coupled to compute

games.

Participants received a program of dynamic balance exercises coupled with video game play, using a center-of-pressure position signal as the computer mouse. The tasks were performed while standing on a fixed floor surface, with progression to compliant foam. Three games were developed for use (under pressure, memory match and

balloon burst)

Individual sessions $2 x /$ week (45 min each session) for 4 weeks.

CG: Typical rehabilitation program at day hospital.

Thera-Band and leg weights were used

for strength exercises, and a cycle ergometer was used for endurance exercise. Balance exercises included hip flexion, side-leg raises, squats, and standing up from a chair and sitting down in the chair without using hands. Along with these exercises, there was an assessment of walking aids and a gait re-education program.

Participants also were involved in an unsupervised walking program.

- Significant within-group and between group improvements in BBS scores were observed. Significant reductions in LOB counts on the foam surface and $A B C$ scores were observed for the $\mathrm{EG}_{\text {, but }}$ not for the CG.

- The EG exhibited significantly greater improvements in change scores for the $B B S, A B C, L O B$ than the CG.

- No significant within-group or between-group effect on spatiotemporal gait parameters and for the composite $L O B$ on normal surface.

- At baseline there was a significant group difference in TUG time, with a worse time among the EG. Although improvements in TUG time did occur in both groups, the differences between groups were not significant.

Individual sessions $2 x /$ week, (45 min each session) for 4 weeks. 
Table 2 Data summary of randomized clinical trials using exergames with other devices (Continued)

\begin{tabular}{|c|c|c|c|c|}
\hline & & & - cyclic forward trunk bending. & \\
\hline $\begin{array}{l}\text { Hagedorn } \\
\& \text { Holm } \\
{[32]}\end{array}$ & $\begin{array}{l}\text { Patients from a } \\
\text { geriatric falls and } \\
\text { balance clinic. }\end{array}$ & $\begin{array}{l}\text { Randomized } \\
\text { controlled trial. }\end{array}$ & $\begin{array}{l}\text { 1) Maximal isometric } \\
\text { muscle force: knee } \\
\text { extensor/ flexor muscle } \\
\text { and ankle dorsiflexion. }\end{array}$ & $\begin{array}{l}\text { Both: Both groups received progressive } \\
\text { resistance muscle strength training whit } \\
\text { high intensity, training in step machine, } \\
\text { cycling (at least } 15 \text { min and minimum of } \\
\mathrm{km} \text { ) and ball games (dribbling, rolling and } \\
\text { throwing). Patients were also instructed tc } \\
\text { train endpoints at home when they score } \\
\text { low in a pre-training test. }\end{array}$ \\
\hline
\end{tabular}

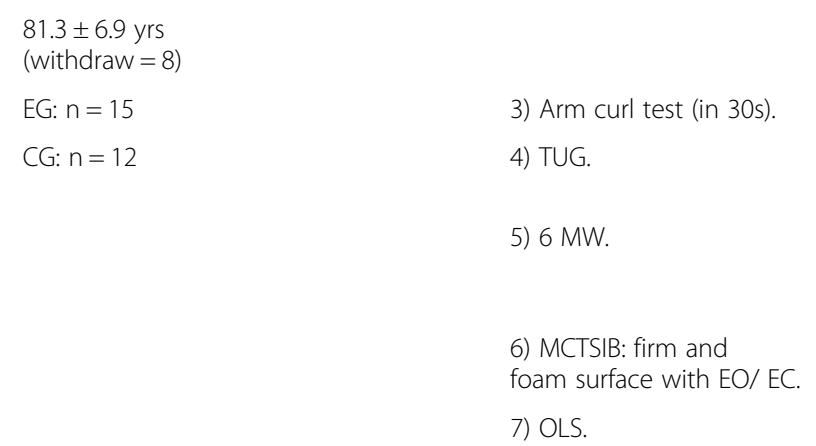

8) Tandem test.

9) BBS.

10) $\mathrm{DGl}$.
Four games were used and controlled through weight shifts. Games:

1- Building a tower used lifting a leg.

2- Bursting a balloon with alternated movements for normal standing to toe.

3- Controlling a tray with a drink by shifting the body position while standing on medium dense foam

4- Catching fruits in a bucket.

Two games were allowed at each training session if they did not exceed about 10 minutes. As patients progressed, the surface was changed to a more difficult one.

Individual session 2/week (1.5 hour each session) for 12 weeks.

CG: Traditional balance training.

Treatment was composed of exercises standing on different surfaces (foam, tilting platforms and pillows) EO/EC, one leg balance training, walking on a line and passing an obstacle course.

11) FES-I.

Individual session 2/week (1.5 hour each
- Within group analyses showed significan improvement after the intervention period on knee extension for both groups. CG had significant improvement on STS and EG for walking distance (6 MW test).

- Comparisons between groups showed significant change in time standing on a foam with EC in favoring of EG. There were no differences between groups for others outcomes. session) for 12 weeks.

$6 \mathrm{MW}=6$ minute walk test; ABC Scale = The Activities-specific Balance Confidence Scale; AST = Alternate Step Test; A-P = Antero - Posterior; BBS = Berg Balance Scale; CG = Control Group; COP = center of pressure; CSRT

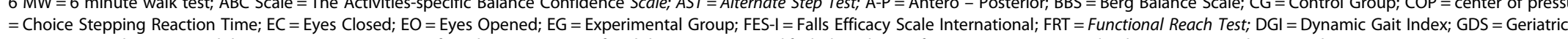

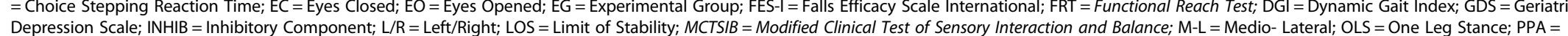
Physiological Profile Assessment: SAFFE = The Survey of Activities and Fear of Falling in the Elderly; STS = Sit to Stand; TUG = Timed Up and Go; TMT = Trail Making Test: VRE =Virtual Reality Environment. 
Table 3 Methodological analysis of exergames in older adults by the PEDro sclale

\begin{tabular}{|c|c|c|c|c|c|c|c|c|c|c|c|c|}
\hline Study & $\begin{array}{l}\text { Eligibility } \\
\text { criteria }\end{array}$ & $\begin{array}{l}\text { Random } \\
\text { allocation }\end{array}$ & $\begin{array}{l}\text { Concealed } \\
\text { allocation }\end{array}$ & $\begin{array}{c}\text { Baseline } \\
\text { comparability }\end{array}$ & $\begin{array}{c}\text { Blind } \\
\text { subjects }\end{array}$ & $\begin{array}{l}\text { Blind } \\
\text { therapists }\end{array}$ & $\begin{array}{c}\text { Blind } \\
\text { assessors }\end{array}$ & $\begin{array}{l}\text { Adequate } \\
\text { follow-up }\end{array}$ & $\begin{array}{c}\text { Intention-to-treat } \\
\text { analysis }\end{array}$ & $\begin{array}{l}\text { Between-group } \\
\text { comparisons }\end{array}$ & $\begin{array}{l}\text { Point estimates } \\
\text { and variability }\end{array}$ & Score \\
\hline $\begin{array}{l}\text { Bieryla \& } \\
\text { Dold [9] }\end{array}$ & yes & yes & no & yes & no & no & no & yes & no & yes & yes & 5 \\
\hline $\begin{array}{l}\text { Duque } \\
\text { et al. [12] }\end{array}$ & yes & yes & no & yes & no & no & yes & no & no & yes & yes & 5 \\
\hline $\begin{array}{l}\text { Schoene } \\
\text { et al. [13] }\end{array}$ & yes & yes & yes & yes & no & no & yes & yes & no & yes & yes & 7 \\
\hline $\begin{array}{l}\text { Franco } \\
\text { et al. [28] }\end{array}$ & yes & yes & no & yes & no & no & no & yes & no & yes & yes & 5 \\
\hline $\begin{array}{l}\text { Jorgensen } \\
\text { et al. [7] }\end{array}$ & yes & yes & no & yes & no & no & yes & yes & yes & yes & yes & 7 \\
\hline $\begin{array}{l}\text { Laver } \\
\text { et al. [29] }\end{array}$ & yes & yes & yes & yes & no & no & yes & yes & yes & yes & yes & 8 \\
\hline $\begin{array}{l}\text { Maillot \& } \\
\text { Perrot [6] }\end{array}$ & yes & yes & no & yes & no & no & no & yes & no & yes & yes & 5 \\
\hline $\begin{array}{l}\text { Pichierri } \\
\text { et al. [30] }\end{array}$ & yes & yes & no & yes & no & no & no & no & no & yes & yes & 4 \\
\hline $\begin{array}{l}\text { Pluchino } \\
\text { et al. [10] }\end{array}$ & yes & yes & yes & yes & no & no & no & no & no & yes & yes & 5 \\
\hline $\begin{array}{l}\text { Rendon } \\
\text { et al. [8] }\end{array}$ & yes & yes & no & yes & no & no & yes & no & yes & yes & yes & 6 \\
\hline $\begin{array}{l}\text { Toulotte } \\
\text { et al. [31] }\end{array}$ & yes & yes & yes & yes & no & no & no & yes & no & no & yes & 5 \\
\hline $\begin{array}{l}\text { Szturm } \\
\text { et al. [11] }\end{array}$ & yes & yes & yes & yes & no & no & yes & yes & no & yes & yes & 7 \\
\hline $\begin{array}{l}\text { Hagedorn } \\
\text { \& Holm [32] }\end{array}$ & yes & yes & no & yes & no & no & no & no & no & yes & yes & 4 \\
\hline
\end{tabular}


inclusion criteria were similar in all the studies analyzed, demonstrating a relative degree of functional independence and cognitive capacity in the participants. The survey conducted by Laver et al. [29] followed the same criteria for inclusion as the other studies, however, the sample is different because the participants were hospitalized due to acute conditions or health complications such as falls, fractures, medical and surgical problems.

\section{Assessed outcomes}

All studies presented some type of measurement related to the primary outcome of this review, be it through the analysis of mobility [6-11,13,29,32], body balance $[9-11,13,28,29,31,32]$ or questionnaires on selfefficacy in activities involving risk of falls [7,8,11-13, $29,30,32]$. For the mobility outcome, the most frequently used instrument was the Timed Up and Go test (TUG) [7,9-11,13,29,32], while for body balance it was the Berg Balance Scale (BBS) $[9,11,28,29,32]$ and for self-efficacy it was the Falls Efficacy Scale (FES/ FES-I) [7,13,30,32]. Other tests and instruments related to the primary outcome, were Sit to Stand 5 (STS) or Chair Stand Test [6,7,13,32], The Activities-specific Balance Confidence Scale (ABC scale) $[8,11,29]$, Tinetti Performance Oriented Mobility Assessment (POMA) [10,28,31], One Leg Stance (OLS) $[10,31,32]$, Functional Reach Test (FR) [9,10], The Survey of Activities and Fear of Short Physical Battery (SPPB) [29], Dynamic Gait Index (DGI) [32], Physiological Profile Assessment (PPA) [13] and Falling in the Elderly (SAFFE) [12].

With regard to the secondary outcomes of this review, the most frequently assessed measures were muscle strength $[7,12,32]$; gait $[11,12,30]$, postural control $[7,10,12,31]$ and other parameters $[13,30]$ through the use of laboratory equipment. Outcomes assessed with lesser degree of representation in the studies were questionnaires on daily living activities [29], quality of life $[28,29]$, cognition $[6,13]$, depression $[8,12]$, aerobic capacity [32] and history of falls.[10] In some studies, the participants in the exergames group were asked about discomfort and adverse events [29], impressions of the game [6], enjoyment [28] and motivation [7].

\section{Study design and methodological quality}

Ten studies described themselves as Randomized Controlled Trials [6-9,11,12,28,30-32] and three studies as Randomized Controlled Trial - Pilot Studies [10,13,29]. Just one study performed analysis of the short-term follow-up (one month after the intervention period) [6]. In the study by Duque et al. [12] during the follow-up, the participants in the exergame group continued to receive their usual care. Thus, no long-term follow-up was performed in any of the studies.
All studies included in this review had their PEDro score retrieved from the PEDro website, since they had been ranked previously (Table 3 ). Studies scores show that most of the studies presented methodological problems, with a high proportion of scores below 5 $[6,9,10,12,28,30-32]$.

\section{Intervention protocol}

The exergames groups used games through Nintendo Wii gaming console [6-10,28,29,31] (Table 1), games created on computers [11,32], Dance video game with pad $[13,30]$ and the Balance Rehabilitation Unit (BRU $\left.{ }^{\mathrm{TM}}\right)$ [12] (Table 2).

Some studies added to the exergames group recommendations for falls prevention [12], warm-up and cool-down exercises [10], adapted physical activity [31], home exercises [28], exercises for balance, muscle resistance and strengthening [30,32].With the exception of one study that administered the games in pairs [6], the other studies performed the exergames individually. Pichierri et al. [30] combined the exergames performed individually with a group intervention using conventional exercises. In only one study, the participants were instructed to use the exergames at home, with no professional supervision during the sessions [13].

In six studies there was a control group with no type of intervention $[6,8,9,13,28,31]$. The study by Jorgensen et al. [7] had a placebo control group, using EVA insoles with no therapeutic effect. When the control group was active, the therapies performed involved physical activity, conventional physiotherapy, traditional balance training and usual care [10-12,29-32]. Also with regard to the control group, specific protocols and techniques were used, such as Matter of Balance (MOB) [28] and Tai Chi [10]. Three studies delivered group interventions as control $[10,28,30]$.

The time of exergames intervention varied from $10 \mathrm{mi}-$ nutes to an hour, with a predominance of therapies with an average time of 30 minutes. For the studies involving some type of intervention in the control group, the time varied from 25 minutes to an hour. The total duration of treatment varied from 3 to 20 weeks and the frequency of the sessions was from 1 to 5 times a week.

\section{Effects of the intervention}

For the studies that compared exergames and active control, no difference was observed between groups in two of the studies $[10,28]$. The other studies demonstrated improvements favoring the exergame group in some of the outcomes assessed, such as laboratory outcomes related to gait and posture control [12,30,31], balance $[11,29]$, mobility [29] and self-efficacy for falls [11,12].

In the study with the placebo control (EVA insole), there was improvement in the parameters relating to 
muscle strength, mobility and self-efficacy for falls [7]. The studies that used comparison with non-active control group observed differences only in some specific parameters related to balance $[8,9]$, mobility $[6,8,13]$, muscle strength [6], reaction time [13] and physiological functions involved in postural stability [13] in favor of the exergame group. In one study with three arms: a group using Wii Fit games, an MOB intervention group and a non-active control group it was observed a balance improvement in all groups with no difference between them [28].

For the TUG, the instrument most used by the studies included in this review, three studies indicated improvement in favor of the exergame group $[7,13,29]$, one study did not observed a superiority in favor of the exergame group [11] and the others studies did not observed any improvement in any of the groups $[9,10,32]$. With regard to the BBS, three studies obtained significant improvement from interactive game group in comparison with the control group $[9,11,29]$, being that Bieryla \& Dold [9] observed this improvement only in the follow-up analysis after one month. In the study by Franco et al. [28] there was an increase in the BBS score for the three groups analyzed, but with no significant difference between them. There was no improvement in the results for the BBS in older outpatients from the geriatric and balance clinic [32].

The older adults responded positively in terms of enjoyment and their perception of improvement in functional aspects after practicing the exergames $[6,13,28]$. Four articles demonstrated high levels of adherence to the treatments $[6,12,13,30]$. Two studies reported that there were no adverse effects during intervention with the use of games [7,13] while Laver et al. [29] reported cases of discomfort for the exergames group and for the control group that used conventional therapy.

\section{Discussion}

The use of technologies that allow the creation of interactive environments and that provide a form of treatment for the older population by way of VR is spreading worldwide. However, as shown in this review, there is still no substantial evidence of improvement in physical functioning among older adults through the use of exergames, either as a complementary form or as an alternative to other types of intervention.

This systematic review included studies that used different VR technologies to administer the therapies with interactive games. The Nintendo ${ }^{\mathrm{Tm}}$ Wii (Nintendo; Redmond, WA, USA) console was the one most frequently used to apply the games [6-10,28,29,31] with variations depending on the package and accessories used such as the Wii Sports package with the associated handheld remotes and the balance, fitness and strength games in the Wii Fit package with the accompanying Wii balance board. Some studies used more sophisticated VR systems, such as the computer feedback system (Personics, Äbyh Øj Denmark) coupled to sensors that register body position [32], BRU ${ }^{\mathrm{Tm}}$ a force platform used to assess (posturography) and train balance [12], and computer games coupled to the flexible pressure mat (FSA pressure mat, Vista Medical td, Winnipeg.) developed exclusively for the study [11]. Another VR option was the use of step pads with the modified Dance Dance Revolution (DDR) Stepmania game [13,30].

With the exception of BRU, which requires specific training for implementation, has a high cost and depends on ample space and safety accessories, even those that make use of specific computer programs represent a relatively simple form of intervention with virtual games. It is notable that the studies give priority to the games available on commercial consoles that facilitate their use in therapeutic environments and participant access to the equipment if they wish to continue the activities after the study.

According to the World Health Organization [33], the regular practice of physical activities among older adults can prevent against diseases and disability, including tasks of transportation (e.g. walking or cycling), occupational, household chores, play, games, sports or planned exercise, in the context of daily, family and community activities. The use of interactive games through VR can be, therefore, considered as a form of physical activity and this way should obey recommendations related to period and length of practice, to bring the desired benefits to the health of the older person.

The directives of the Global Recommendations on Physical Activity for Health [33] recommend that older people practice at least 150 minutes of moderately aerobic physical activity or at least 75 minutes of vigorously aerobic physical activity over the course of a week. Also according to this guideline, the elderly should carry out activities for muscular strengthening involving large major muscle groups twice a week or more. In the case of older individuals with reduced mobility, an exercise program should be followed three times a week, aimed at improving balance and preventing falls. However, in the case of interactive games there are still no references with regard to the time of intervention needed for functional improvement.

In the studies analyzed in this review, the interventions demanded movements in an orthostatic position which we considered to represent moderately intense physical activity. This being so, none of the studies attained the minimum length of practice time recommended for the older population. This data corroborates the findings of other systematic reviews on VR subject, testifying the lack of standardization in dosage 
for this type of intervention for therapeutic purposes $[21,34]$.

The VR games were administered on an isolated basis $[6-9,11,13,29]$ or combined with conventional physical activities [10,12,28,30-32]. Concepts related to learning and motor control consider that practice involving functional tasks that are identifiable through variable practices and with the presence of contextual interferences ensure greater transfer of the task practiced to new tasks and new environments [35]. Interventions that bring together several components such as strength training, resistance, balance exercises, cognitive elements and education stimulate the older person on a broader level and prevent disability [36]. Ultimately, the use of exergames associated with multiple components and variable practice may result in improved functionality and greater gains in the process of rehabilitation compared with practices conducted on a single basis.

With regard to the assessment instruments, a large part of the studies included in this review chose methods that are widely used in the older population, such as BBS, TUG, FR and POMA. These instruments can be applied in a range of therapeutic environments; they do not require complex materials, extended lengths of time for administration and they are low-cost. These characteristics facilitate their use in clinical practice. Nevertheless, some of these instruments might have problems with responsiveness. This fact may be caused, in some of the studies by a ceiling effect on the scores in the baseline assessment, justifying the lack of significant difference between the game intervention group and the control group $[9,28]$.

As presented in the results, the studies included in this review registered specific improvements in some measures relating to physical functioning. Studies that use assessment based on posturography and gait analysis detected improvements in quantitative laboratorial parameters $[12,30,31]$. These parameters are more sensitive to change, but these gains are not always transferred to the activities assessed in the functional capacity tests. Also, little is known about the differences that are clinically relevant for these instruments. With regard to the instruments, of the seven studies analyzed that had their outcomes assessed by the TUG [7,9-11,13,29,32], just two of them revealed significant improvement in the group that had intervention of exergames in relation to the control group $[7,29]$. In the study by Laver et al. [29] the group that had intervention with Nintendo Wii obtained better results than the traditional hospital therapy group after adjustments to hospital length of stay, age, sex and baseline functional independence measure. Jorgensen et al. [7] compared intervention through Nintendo Wii Training with a placebo. It is worth pointing out that for those who encountered no significant differences between the groups post-intervention, or the test result was within the normal range prior to intervention $[9,10,13]$, or the groups presented differences in the baseline [11,32]. With regard to the BBS, just one study encountered an improvement in favor of the exergame group in comparison with the control group [11]. Franco et al. [28], observed improvement both in the intervention group and in the control group, without any significant difference between them. In the other studies there was no significant difference in the BBS scores between exergame and the control group in the post-intervention period [9,32]. However, one point that appears to be a consensus is the motivation that the use of VR through interactive games provides $[6,13,28]$. Because it involves tasks that combine physical and cognitive demands in an attractive and challenging way, interactive games may represent an option that is both viable and well-accepted by older people, thereby expanding the therapeutic strategies used in conventional physiotherapy.

Although this review has only chosen randomized clinical trials, aiming to attain better scientific evidence, the studies selected present methodological limitations, and consequently restricting their capacity for generating evidence regarding the efficacy of intervention with VR games. The most frequent limitation is related to the sample size and its characteristics. In order to render the use of interactive games viable, inclusion criteria were applied to ensure a relative degree of physical and cognitive independence of the older adults. This not only makes it more difficult to recruit such participants but also limits the representativeness of the sample, portraying a very specific parcel of the older population within the chosen therapeutic scenarios. The absence of sample size calculation may culminate in systematic errors $[37,38]$ and the small sample size along with the restrictions in the inclusion criteria reduce the external validity of the study, i.e. that the results of the surveys studies are limited for population generalization. Only three studies performed the intention-to-treat analysis $[7,8,29]$ which protects the randomization and preserves compatibility between groups, thereby reducing the chance of bias [39]. Also, the studies used in this review cannot categorically state that the gains observed would lead to lasting benefits for the participants, since no follow-up analysis was performed.

These limitations have been quantified and are expressed by low scores on the PEDro scale. Although the criteria for eligibility, random allocation, baseline comparability, point estimates and variability have been adopted; the absence of intention-to-treat analysis, blinding and follow-up in a large part of the studies result in low scores and indicate poor methodological quality. The other reviews published on VR come up against similar problems $[17,21,23,34]$. 


\section{Conclusion}

This manuscript brings a critic view of studies involving the use of exercises using interactive games (exergames) in improving physical functioning in older. Resources involving VR are growing in interest and the use of exergames has shown the potential to represent an option that is both viable and well-accepted by older people. However the results discussed in this review show that evidence to support the effectiveness of using exergames for improving physical functioning in older adults remains inconclusive.

In order to achieve better methodological quality and provide stronger scientific evidence, it is necessary that future studies use more responsive instruments with clear minimal clinically important difference, as well as conduct appropriate statistical analyses and sample size calculations. We observed that there was a wide variability in exercise prescription regarding the use of exergames, ultimately making a suitable dosage of training still inconceivable. It is recommended that RCTs should follow the Consolidated Standards of Reporting Trials [40], since it was challenging to retrieve relevant information in some studies. Therefore, it is still not possible to recommend the use of exergames as an isolated or combined intervention for improving physical functioning in older people.

\section{Competing interests}

The authors declare that they have no competing interests.

\section{Authors' contributions}

KIM, NAR and MRP were involved in the conception and design of the review, the search and analysis and interpretation of the studies, and the writing of the manuscript. SAM was the second reviewer to carry out the quality assessment on the relevant articles with KIM and was involved in revising of the manuscript. The final manuscript has been seen and approved by all author.

\section{Acknowledgement}

In this review everyone involved in conception, design, search and analysis or interpretation of data were involved in drafting or revising the manuscript, and were considered as co-authors. Therefore, we don't have anyone else to acknowledge.

Received: 28 May 2014 Accepted: 31 October 2014

Published: 15 November 2014

\section{References}

1. de Bruin ED, Schoene D, Pichierri G, Smith ST: Use of virtual reality technique for the training of motor control in the elderly. Some theoretical considerations. Z Gerontol Geriatr 2010, 43:229-234.

2. Levin MF: Can virtual reality offer enriched environments for rehabilitation? Expert Rev Neurother 2011, 11:153-155.

3. Guderian B, Borreson LA, Sletten LE, Cable K, Stecker TP, Probst MA, Dalleck LC: The cardiovascular and metabolic responses to Wii Fit video game playing in middle-aged and older adults. J Sports Med Phys Fitness 2010, 50:436-442.

4. American College of Sports M, Chodzko-Zajko WJ, Proctor DN, Fiatarone Singh MA, Minson CT, Nigg CR, Salem GJ, Skinner JS: American college of sports medicine position stand. Exercise and physical activity for older adults. MSSE 2009, 41:1510-1530
5. Bisson E, Contant B, Sveistrup H, Lajoie Y: Functional balance and dual-task reaction times in older adults are improved by virtual reality and biofeedback training. Cyberpsychol Behav 2007, 10:16-23.

6. Maillot P, Perrot A, Hartley A: Effects of interactive physical-activity videogame training on physical and cognitive function in older adults. Psychol Aging 2012, 27:589-600.

7. Jorgensen MG, Laessoe U, Hendriksen C, Nielsen OB, Aagaard P: Efficacy of Nintendo Wii training on mechanical leg muscle function and postural balance in community-dwelling older adults: a randomized controlled trial. J Gerontol A Biol Sci Med Sci 2013, 68:845-852.

8. Rendon AA, Lohman EB, Thorpe D, Johnson EG, Medina E, Bradley B: The effect of virtual reality gaming on dynamic balance in older adults. Age Ageing 2012, 41:549-552.

9. Bieryla KA, Dold NM: Feasibility of Wii Fit training to improve clinical measures of balance in older adults. Clin Interv Aging 2013, 8:775-781.

10. Pluchino A, Lee SY, Asfour S, Roos BA, Signorile JF: Pilot study comparing changes in postural control after training using a video game balance board program and 2 standard activity-based balance intervention programs. Arch Phys Med Rehabil 2012, 93:1138-1146.

11. Szturm T, Betker AL, Moussavi Z, Desai A, Goodman V: Effects of an interactive computer game exercise regimen on balance impairment in frail community-dwelling older adults: a randomized controlled trial. Phys Ther 2011, 91:1449-1462.

12. Duque G, Boersma D, Loza-Diaz G, Hassan S, Suarez H, Geisinger D, Suriyaarachchi P, Sharma A, Demontiero O: Effects of balance training using a virtual-reality system in older fallers. Clin Interv Aging 2013, 8:257-263.

13. Schoene D, Lord SR, Delbaere K, Severino C, Davies TA, Smith ST: A randomized controlled pilot study of home-based step training in older people using videogame technology. PLoS One 2013, 8:e57734.

14. Booth V, Masud T, Connell L, Bath-Hextall F: The effectiveness of virtual reality interventions in improving balance in adults with impaired balance compared with standard or no treatment: a systematic review and meta-analysis. Clin Rehabil 2013, 28:419-431.

15. Seidler RD, Bernard JA, Burutolu TB, Fling BW, Gordon MT, Gwin JT, Kwak Y, Lipps DB: Motor control and aging: links to age-related brain structural, functional, and biochemical effects. Neurosci Biobehav Rev 2010, 34:721-733.

16. Heuninckx S, Wenderoth N, Swinnen SP: Systems neuroplasticity in the aging brain: recruiting additional neural resources for successful motor performance in elderly persons. J Neurosci 2008, 28:91-99.

17. van Diest M, Lamoth CJ, Stegenga J, Verkerke GJ, Postema K: Exergaming for balance training of elderly: state of the art and future developments. J Neuroeng Rehabil 2013, 10:101.

18. Govercin M, Missala IM, Marschollek M, E S T: Virtual rehabilitation and telerehabilitation for the upper limb: a geriatric review. GeroPsych: J Gerontopsychol Geriatr Psychiatry 2010, 23:79-90.

19. Holden MK: Virtual environments for motor rehabilitation: review. Cyberpsychol Behav 2005, 8:187-211. discussion 212-189.

20. Imam B, Jarus $T$ : Virtual reality rehabilitation from social cognitive and motor learning theoretical perspectives in stroke population. Rehabil Res Pract 2014, 2014:594540.

21. Miller KJ, Adair BS, Pearce AJ, Said CM, Ozanne E, Morris MM: Effectiveness and feasibility of virtual reality and gaming system use at home by older adults for enabling physical activity to improve health-related domains: a systematic review. Age Ageing 2013, 43:188-195.

22. Pietrzak E, Cotea C, Pullman S: Using Commercial Video Games for Falls Prevention in Older Adults: The Way for the Future? J Geriatr Phys Ther 2014, 37:166-177.

23. Saposnik G, Levin M, Outcome Research Canada Working G: Virtual reality in stroke rehabilitation: a meta-analysis and implications for clinicians. Stroke 2011, 42:1380-1386.

24. Verheijden Klompstra L, Jaarsma T, Stromberg A: Exergaming in older adults: a scoping review and implementation potential for patients with heart failure. Eur J Cardiovasc Nurs 2014, 13:388. 398.

25. Erren-Wolters CV, van Dijk H, de Kort AC, ljzerman MJ, Jannink MJ: Virtual reality for mobility devices: training applications and clinical results: a review. Int J Rehabil Res 2007, 30:91-96.

26. Shiwa SR, Costa LOP, Moser ADL, Aguiar IC, Oliveira LVF: PEDro: a base de dados de evidências em fisioterapia. Fisioter mov 2011, 24:523-533.

27. PEDro Physiotherapy Evidence Database. http://search.pedro.org.au/. 
28. Franco JR, Jacobs K, Inzerillo C, Kluzik J: The effect of the Nintendo Wii Fit and exercise in improving balance and quality of life in community dwelling elders. Technol Health Care 2012, 20:95-115.

29. Laver K, George S, Ratcliffe J, Quinn S, Whitehead C, Davies O, Crotty M: Use of an interactive video gaming program compared with conventional physiotherapy for hospitalised older adults: a feasibility trial. Disabil Rehabil 2012, 34:1802-1808.

30. Pichierri G, Murer K, de Bruin ED: A cognitive-motor intervention using a dance video game to enhance foot placement accuracy and gait under dual task conditions in older adults: a randomized controlled trial. BMC Geriatr 2012, 12:74.

31. Toulotte C, Toursel C, Olivier N: Wii Fit(R) training vs. Adapted physical activities: which one is the most appropriate to improve the balance of independent senior subjects? a randomized controlled study. Clin Rehabil 2012, 26:827-835.

32. Hagedorn DK, Holm E: Effects of traditional physical training and visual computer feedback training in frail elderly patients. A randomized intervention study. Eur J Phys Rehabil Med 2010, 46:159-168.

33. Global Recommendations on Physical Activity for Health. http://www.who.int/ dietphysicalactivity/factsheet_recommendations/en/.

34. Virk S, McConville KM: Virtual reality applications in improving postural control and minimizing falls. Conf Proc IEEE Eng Med Biol Soc 2006, 1:2694-2697.

35. Shumway-Cook A, Woollacott M: Motor Control: Translating Research into Clinical Practice. 3rd edition. Philadelphia: Lippincott Williams \& Wilkins; 2007.

36. Freiberger E, Haberle L, Spirduso WW, Zijistra GA: Long-term effects of three multicomponent exercise interventions on physical performance and fall-related psychological outcomes in community-dwelling older adults: a randomized controlled trial. J Am Geriatr Soc 2012, 60:437-446.

37. Costa LO, Maher CG, Lopes AD, de Noronha MA, Costa LC: Transparent reporting of studies relevant to physical therapy practice. Rev Bras Fisioter 2011, 15:267-271.

38. Clark T, Berger U, Mansmann U: Sample size determinations in original research protocols for randomised clinical trials submitted to UK research ethics committees: review. BMJ 2013, 346:f1135.

39. White IR, Horton NJ, Carpenter J, Pocock SJ: Strategy for intention to treat analysis in randomised trials with missing outcome data. BMJ 2011 342:d40.

40. CONSORT Statement Website. http://www.consort-statement.org/.

doi:10.1186/1743-0003-11-156

Cite this article as: Molina et al.: Virtual reality using games for improving physical functioning in older adults: a systematic review. Journal of NeuroEngineering and Rehabilitation 2014 11:156.

\section{Submit your next manuscript to BioMed Central and take full advantage of:}

- Convenient online submission

- Thorough peer review

- No space constraints or color figure charges

- Immediate publication on acceptance

- Inclusion in PubMed, CAS, Scopus and Google Scholar

- Research which is freely available for redistribution

Submit your manuscript at www.biomedcentral.com/submit
C Biomed Central 